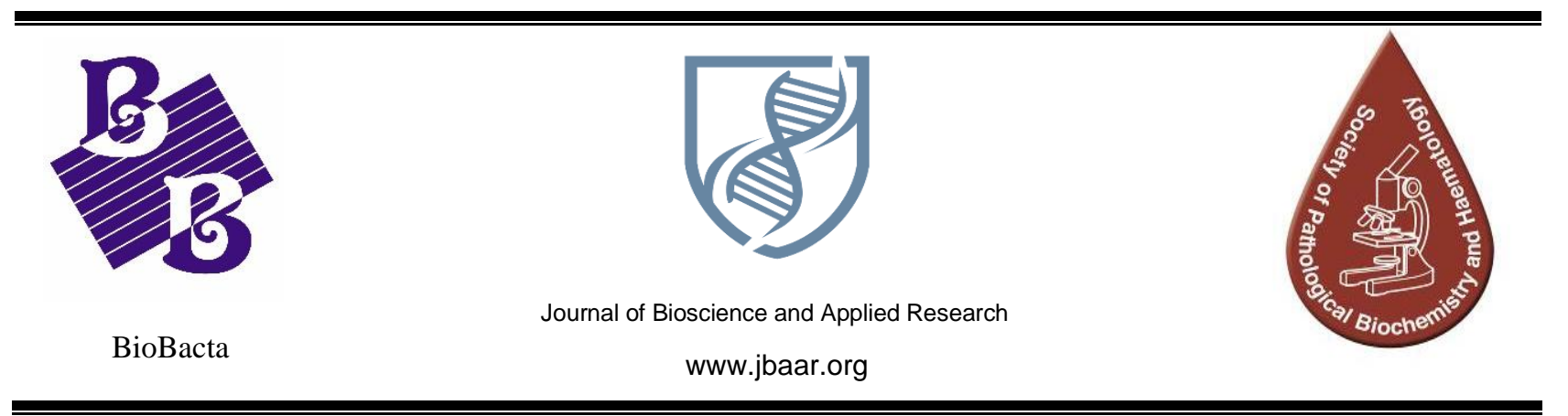

\title{
Gender Differences in the Management of Hazardous Biological Material in Medical Teaching Laboratories
}

\section{Lamia Yaqoub Mohammed, Raghad Hassan Hussein Sanyi, Izzat Abdulsatar Mezher Al-Rayahi}

College of Health and Medical Technology, Middle Technical University, Baghdad, Iraq.

Corresponding author: lym433@gmail.com

Received: November 5, 2019; Accepted: December 10, 2019

DOI: $10.21608 /$ jbaar.2019.115567

\begin{abstract}
Hazardous waste of medical or research laboratory origin is a potential source of contamination to the environment. Untreated waste could contribute to the prevalence of various antibiotic-resistant human opportunistic pathogens. Efficient and proper handling and disposal of biological and clinical waste increases the biosafety of these facilities and reduce any potential threat to the environment. The aim of this study was to determine any gender difference in the management of hazardous biological materials among workers in medical teaching laboratories. The study included 75 participants, $56 \%$ of whom were females and $44 \%$ were males. A questionnaire including 4 sections was distributed among the participants. The results of the study found no gender difference in the participant's knowledge of the international biohazard and safety symbols and compliance with the recommended hazardous waste disposal procedures. In contrast, incident reporting was significantly higher among males $(\mathrm{p}<0.05)$. Extensive training programs and regular review of biosafety policy in teaching medical laboratories are required.
\end{abstract}

Keywords: hazardous waste, research laboratory, biosafety.

\section{Introduction}

The efficient handling of hazardous waste of university/institutional laboratory origin is necessary to limit the spread of occupational acquired illness among laboratory workers and the potential dissemination of these illnesses to the public [1]. In this regard, hazard identification, appropriate laboratory techniques, individual awareness of PPE (personal protective equipment), incident reporting, the use of appropriate containment measures and risk assessment of laboratory techniques are all means of biosafety in the individual laboratories $[2,3]$. A previous report in the United States has documented that inappropriate 
handling of pathogens in university laboratories could lead to the infection of laboratory workers stressing the importance of safe handling of hazardous materials in university settings [4, 5]. Assessment of the awareness regarding biorisk and chemical safety among academic laboratory workers in Iraq carried out during the last couple of years has reported that the standard requirements for safe waste disposal are not all met by those laboratories in which the studies were carried on [6-8]. Nevertheless, we cannot underestimate all the efforts that the Iraqi authorities and their international partners have put into improving the standards of laboratory safety in Iraqi hospital/health centers and educational laboratories and thus minimizing any threat to the environment and the public imposed by these settings [9]. The limited resources of developing countries is a major problem which has led to the handling and disposal of hazardous waste with the general wastes [2]. Gender differences in the perception of safety risks has been reported linking females with lower levels of risk tolerance [10]. Furthermore, health-associated risks have been reported to be more important to females than males and thus it would be expected that females would show higher compliance with the recommended hazardous material disposal procedures. To the best of our knowledge, this the first study which was aimed at identifying any gender differences in hazardous waste management in Iraqi academic laboratories.

\section{Methods}

The study included 75 laboratory workers who worked in 11 universities/institutional laboratories in Baghdad which generate hazardous waste. The study was carried out during the summer of 2018. The objectives of the study were explained to all participants who gave their consent to participate in the study.

A questionnaire including 4 sections was distributed among those workers. The first section included questions to assess the general demographic and educational characteristics of the participants. While the second section was designed to assess their knowledge and recognition of biohazard and safety symbols, the third section was to assess the participant's compliance with the recommended hazardous waste disposal procedures. The last section was to assess incident reporting among the participants. The questionnaire comprised of closed-ended questions except for the questions in the first section. Confidentiality of all participants was maintained.

\section{Statistical analysis}

Microsoft Excel and Graph Pad Prism 5 were used to analyze and present data. Statistical significance of the data was investigated using Fisher's Exact test. A Pvalue $<0.05$ was considered significant.

\section{Results}

Analysis of the data showed that $56 \%$ of the participants were females and $44 \%$ were males with a non-significant difference between the two groups. The majority of males who participated in the study had a $\mathrm{PhD}$ degree $(48.5 \%$ ), while $24.2 \%$ and $27.3 \%$ had BSc and MSc respectively. On the other hand, the majority of female participants had an MSc degree (42.9\%), while $21.4 \%$ and $35.7 \%$ of female participants had BSc and $\mathrm{PhD}$ degrees respectively as shown in Table 1. 
Table 1: Demographic and Educational characteristics of the participants

\begin{tabular}{|c|c|c|c|}
\hline \multicolumn{2}{|c|}{ Gender } & Male (\%) & Female (\%) \\
\hline \multirow{3}{*}{$\begin{array}{c}\text { Educational } \\
\text { Level }\end{array}$} & BSc & 24.2 & 21.4 \\
\cline { 2 - 4 } & MSc & 27.3 & 42.9 \\
\cline { 2 - 4 } & PhD & 48.5 & 35.7 \\
\cline { 2 - 4 } & total & $\mathbf{4 4}$ & $\mathbf{5 6}$ \\
\hline
\end{tabular}

The study revealed that $57 \%$ of female participants were able to recognize the international biohazard and safety symbols while only $48 \%$ of male participants were are able to do so with a non-significant difference between the two genders as illustrated by figure 1 .

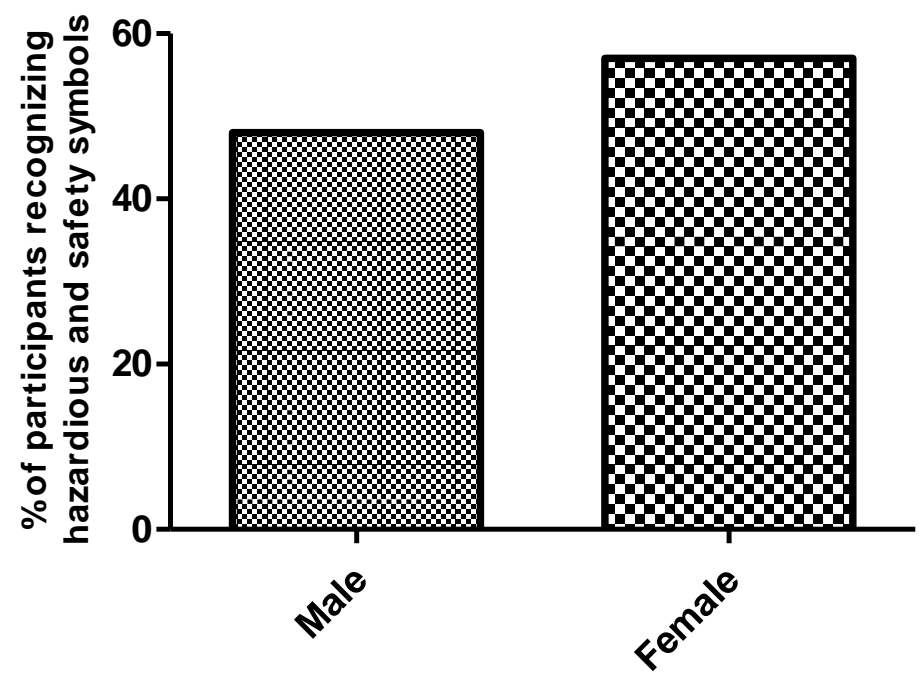

Figure 1: Recognition of the international biohazard and safety symbols 
Figure 2 shows the participant's compliance with the recommended hazardous waste disposal procedures which was $79 \%$ among male participants and $73 \%$ among female participants with a non-significant difference.

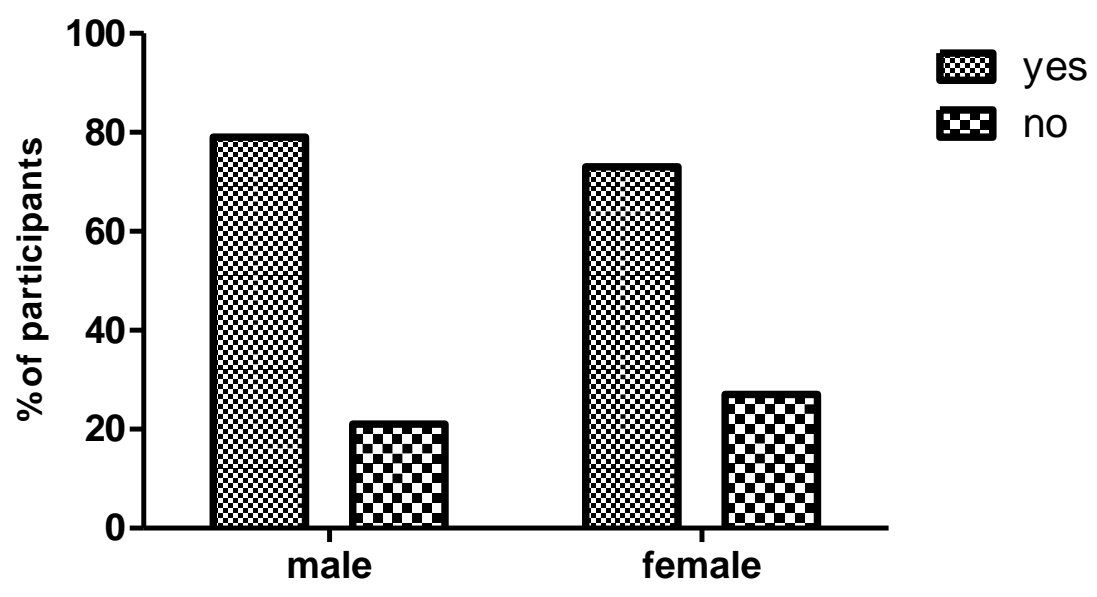

Figure 2: compliance of participants with the recommended hazardous waste disposal procedures

Data on incident reporting (illustrated by figure 3) revealed that reporting of incidents and accidents in the laboratory was higher among male laboratory workers than among their female counterparts (75 and 60\% respectively ) with a significant difference among the two genders $(\mathrm{p}<0.05)$.

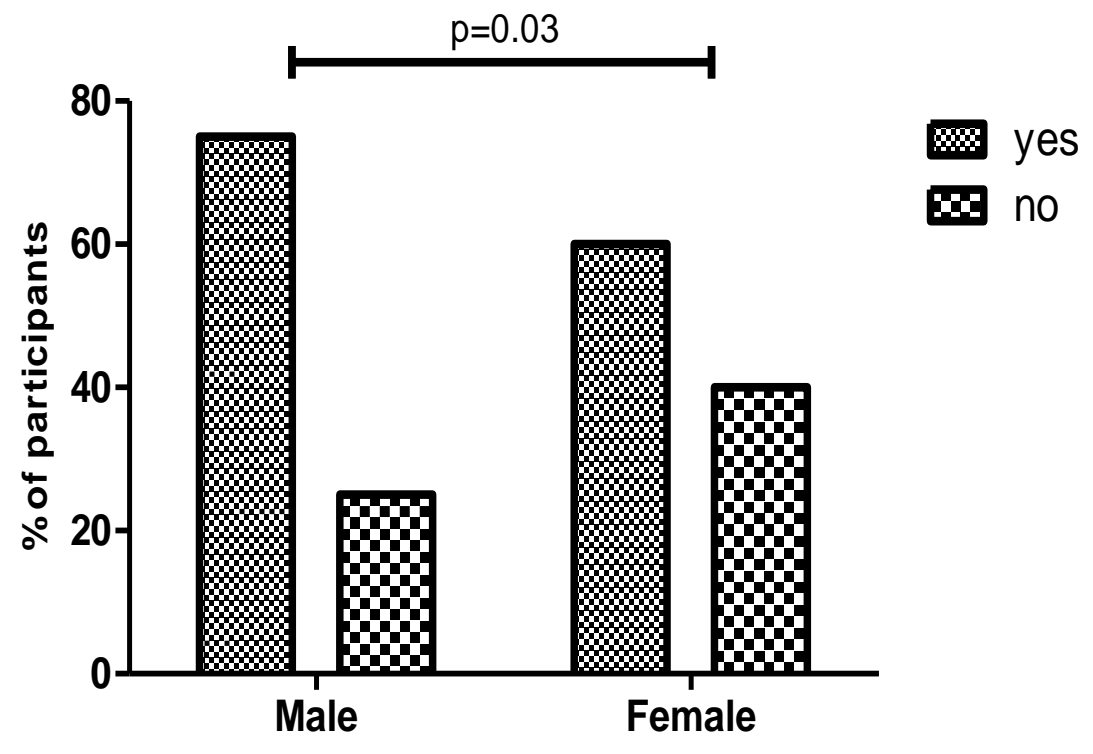

Figure 3: Incident reporting among Laboratory workers according to gender. 


\section{Discussion}

Biohazardous material is any material containing infectious/potentially infectious substances. Efficient handling and disposal of these materials are necessary for ensuring the safety of laboratory workers and the prevention of infectious microorganism dissemination to the public and environment [11]. The implementation of standardized biological waste management policy has been the focus of many academic institutes worldwide [12, 13]. Nevertheless, due to limited resources, developing countries have not given sufficient attention to waste management issues $[1,14]$. Recent years have witnessed a focus of academic institutes on the biosafety of their facilities [12]. A number of studies addressing the level of biosafety compliance in Iraqi academic facilities have been published. Although improvement in the biosafety of these facilities has been recorded much work is needed to ensure that all the recommended international biosafety measures are implemented [6, $7,15]$. The WHO has published a biosafety manual outlining all the basics of laboratory biological safety which is considered a guide for safe laboratory practice [16].

This study included 75 participants who worked in 11 university laboratories. Of those participants, 56\% were females and $44 \%$ were males with a nonsignificant difference between them. Most females carried an MSc degree, while most of the males carried a $\mathrm{PhD}$ degree. International biohazard and safety symbols recognition indicates the segregation of hazardous waste from non-hazardous waste, in addition to the implementation of biosafety concepts [2]. These symbols were recognized by $57 \%$ of female participants and $48 \%$ of male participants indicating that more awareness of these symbols is needed. This can be accomplished by focused on biosafety training sessions. Two previous studies have concluded that recognition of international biohazard symbols was associated with a higher level of education [2, 17]. Although compliance with the recommended hazardous waste disposal procedures was slightly higher among male participants this did not reach statistical significance. Male participants tend to report laboratory incidence more than females. This was unexpected as previous studies have associated females with reporting higher levels of risk as a concern [10]. One possible reason for this result may be that a higher percentage of the male had attended biosafety training courses/ sessions (data not shown) implying the importance of these training sessions.

In conclusion, no significant gender difference in hazardous waste management was noticed except for incident reporting. Extensive biosafety training sessions are recommended for all workers in medical teaching laboratories. Moreover, annual laboratory inspections and revision of biosafety training requirements are necessary to improve the biosafety level of Iraqi medical teaching laboratories.

Acknowledgement: All the participants of the study are acknowledged for their input.

Disclosures: The authors declare that they have no conflicts of interest.

\section{$\underline{\text { References }}$}

1. Chamberlain AT, Burnett LC, King JP, Whitney ES, Kaufman SG, Berkelman RL. Biosafety Training and Incident-reporting Practices in the United States: A 2008 Survey of Biosafety Professionals. Appl Biosaf. 2009;14(3):135-143.

2. Maina SM, Andrew NK, and C. WN., Assessment of Level of Knowledge in Medical Waste Management in Selected Hospitals in Kenya. .Appli Micro 2016. 2(4): p. 124. doi: 10.4172/2471-9315.1000124

3. Kapoor D, Nirola A, Kapoor V, Gambhir RS. Knowledge and awareness regarding 
biomedical waste management in dental teaching institutions in India- A systematic review. J Clin Exp Dent. 2014;6(4):e419-24. doi:10.4317/jced.51565

4. Lawler, A., Biodefense labs. Boston University Under Fire for Pathogen Mishap. Science, 2005.307(5709):p.501. doi: 10.1126/science.307.5709.501a

5. Investigation update: human Salmonella Typhimurium infections associated with exposure to clinical and teaching microbiology laboratories. 2012, Centers for Disease Control and Prevention Atlanta, GA.

6. AL-Ibadi, M.A., The Chemical Safety and Security in the University of Kufa: Progress and Challenges. Iraqi National Journal Of Chemistry, 2016. 16(2): p. 96-105.

7. ALmamoori, A.M., A. ALfallujI, and B.M. ALhusseini, Evaluation of Chemical and Biological Safety and Security level at the University of Babylon Labs. Iraqi National Journal of Chemistry, 2017. 17(3): p. 157-165.

8. Kareem, S.M., Hamzah, I.H. and Abbas, H.H. Assessment of Awareness Level about Bio Risk Management among Staff of Different Academic Laboratories. Iraqi National Journal of Chemistry., 2016. 16(2): p. 123-126.

9. $\mathrm{Al}$ Jewari, M.F. and G.D. Koblentz, Strengthening Biosecurity in Iraq: Development of a National Biorisk Management System. Front Public Health, 2016. 4: p. 25. doi: 10.3389/fpubh.2016.00025

10. Gustafson, P.E., Gender differences in risk perception: theoretical and methodological perspectives. Risk Anal, 1998. 18(6): p. 80511.

11. Rojo-Molinero, E., et al., [Safety in the Microbiology laboratory]. Enferm Infecc Microbiol Clin, 2015. 33(6): p. 404-10.

12. Emmert, E.A., Biosafety guidelines for handling microorganisms in the teaching laboratory: development and rationale. $\mathrm{J}$ Microbiol Biol Educ, 2013. 14(1): p. 78-83. doi: 10.1128/jmbe.v14i1.531

13. National Research Council Committee on Hazardous Biological Substances in the, L., in Biosafety In The Laboratory: Prudent Practices for the Handling and Disposal of Infectious Materials. 1989, National Academy of Sciences.: Washington (DC).

14. Al Balushi, Y.A., et al., Knowledge, Attitude and Practice of Biomedical Waste Management among Health Care Personnel in a Secondary Care Hospital of Al Buraimi Governorate, Sultanate of Oman. Global Journal of Health Science, 2018. 10(3): p. 7083. DOI:10.5539/gjhs.v10n3p70

15. Mohammed, L.Y., Sanyi, R.H., Al-rayahi, I. A. Attitudes of biological waste management among academic personel working in Baghdad. Indian Journal of Public Health Research \& Development, 2018. 9(12):p.848851. DOI:10.5958/0976-5506.2018.01952.6

16. WHO. Laboratory Biosafety Manual 3rd ed. 2004, Geneva: World Health Organization.

17. Basu, M., P. Das, and R. Pal, Assessment of future physicians on biomedical waste management in a tertiary care hospital of West Bengal. J Nat Sci Biol Med, 2012. 3(1): p. 3842. doi: 10.4103/0976-9668.95945 